\title{
The Correlation Between Health Efficiency And The Level Of Vitamin D At Biginers Aged (10-13) Years Old
}

\author{
By \\ Alaa Sayed Nabih Khalil \\ Dep. Of sporting Health ., Faculty of physical education for men . \\ , Helwan University
}

\section{Abstract}

Despite the fact that the available light of the sun throughout the year in Egypt people are experience sedentary unhealthy life style and stay away from exposed their bodies to the sun due to the high temperature and the availability of means of comfort inside the halls and homes and offices ,shield vehicles and places. Moreover, the traditional dress for women and men alike obscure sunlight beneficial for the body, which may increase the likelihood of the risk factors on the Cardio-respiratory and perhaps pave the way for the emergence of some of the symptoms of depression To Investigate the relationship between the elements of the health-related fitness symptoms of depression among Egyptian childrens10-12years old The study sample consisted of 54girls and 42 boys were randomly chosen, muscle strength(Dynamometer of Grip Strength)muscular endurance(Modified sit-up)and flexibility(Modified Flexibility. The Dia Sorin 25-Hydroxy Vitamin D assay consists of twostep procedure were used .The questionnaire was distributed to186 randomly selected to identify the prevalence of depressive symptoms among them before participating in the Summer Club were deficiency in vitamin $\mathrm{D}(<50 \mathrm{M} \mathrm{mol} / \mathrm{L})$. Those females who classified as deficit in vitamin $\mathrm{D}$ was associated with higher fat percent compared to those with normal vitamin D status $(29 \%$ versus $24 \%$; $\mathrm{p}=0.011)$.There were no significant differences in all physical exercise attribute scores ( $p>0.05)$ in females between those with normal and those with low vitamin D levels. These results were also replicated in males except for grip and cardiorespiratory components Our results showed that a high prevalence of the female are deficit in Vitamin D are susceptible to be early diagnosis osteoporosis and in depression due to their vitamin D deficit. This indicates that BIGINERS at this stage should involve in physical activity program and meet

Key words: Sunlight _ Cardio-respiratory _ Unhealthy life style _ Diagnosis osteoporosis 


\section{INTRODUCTION}

Most people reach their "peak bone mass" in their 20s. This is when bones have achieved their maximum density and strength. After peak bone mass is reached, bone density remains stable during adulthood, and then begins to decline. Physicians once thought that reaching this peak depended primarily on diet, including sufficient calcium intake, and exposure to sunlight, which is necessary for production of vitamin $\mathrm{D}$ in the skin. In fact, vitamin D is necessary for the absorption of calcium from food,Ideally, the best place to get vitamin $\mathrm{D}$ is from your skin being exposed to the UV-B that is in normal sunlight.. However, UV-B does not penetrate very deeply into your skin. The darker the pigmentation or more tanned your skin is, the less UV-B penetrates. Window glass allows only 5 percent of the UV-B light range that produces $\mathrm{D}$ to get into your home or car. These circumstances are prevailed in Egypt so one should consider it. Even the timing of your sun exposure is also a major factor. Sun exposure must take place when UV-B is present. The actual degree of your sun exposure is quite complex since it involves knowing the amount of UV-B and one's skin color. This doesn't sound very complex, but the amount of UV-B is not constant. It is a major variable and is influenced by a number of factors: Latitude, Time of Year, Clouds or Pollution, smog and ozone smog or dust as some times happen in Egypt, and altitude It is important to know the level of UV-B exposure. Longer exposure will not increase vitamin $\mathrm{D}$ production, but will increase the danger of skin damage and possible skin cancer. Darker skin pigmentation, application of sunscreen, ageing and clothing can also have a dramatic effect on pre-vitamin D3 production.

Severe vitamin D deficiency softens bones. In children, the result is rickets, characterized by malformed legs. Adults may develop a rare condition called osteomalacia, distinguished by weakened muscles as well as bones.

In addition, $\mathrm{Ca}$ supplementation studies in growing BIGINERS have shown that an increase in $\mathrm{Ca}$ intake is associated with higher bone mineral status in the order of $1 \%$ to $5 \%$, with the effect appearing to be stronger in the pre-pubertal years and the greatest impact being seen in the early months of the supplementation period.(Johnston, et al 1992, Nowson, et al 1997). Ca supplementation in teenage girls with low dietary $(\mathrm{Ca})$ intakes (mean intake $\sim 600 \mathrm{mg} /$ day) was studied and results showed significantly greater bone mineral content/bone mineral density (BMC/BMD) following supplementation of $300 \mathrm{mg} /$ day of $(\mathrm{Ca})$ in fortified fruit juice. (Lambert et al.2000 ). If the results of this study show that hi percentage of low BMD occurred in the sample chosen this could indicate other nutritional factor to be considered especially milk and (ca) supplementation .Stear and Coworkers (UK) showed that (Ca) supplementation (1000 $\mathrm{mg} /$ day) in a total of 131 female adolescents aged 17 years resulted in an increase in bone-size adjusted bone mass; the effect was still persistent at the femoral neck after 14 months of follow-up. Dodiuk, et al (2000) examined the effectiveness of $(\mathrm{Ca})$ supplementation on BMD 5 years after discontinuation of treatment and found that the beneficial effect of short-term (12 months) (Ca) supplementation on BMD in 14-year-old girls was sustained. Supplementation with milk/dairy products/milk-derived products has been shown to improve the nutritional quality of the diet to a much greater extent than that of $(\mathrm{Ca})$ alone. In addition, increased insulin-like-growth factor I (IGF1) levels have been reported in BIGINERS (Bonjour et al 1997) 


\section{Statement of the problem and significance}

The child population is especially at risk for vitamin $\mathrm{D}$ insufficiency/deficiency. Vitamin D and Ca supplementation trials have been shown to significantly reduce fracture rates in the institutionalized and free-living elderly populations, but vitamin $\mathrm{D}$ given as a supplement alone does not appear to be as effective. Because nutrition and exercise are a modifiable pathogenic factors of osteoporosis, which has important practical and public health implications, it's therefore crucial to increase bone density and bone development in BIGINERS Thus, active life style and physical activity outside halls and complex buildings are necessary for BIGINERS and adults.

Many people in Egypt not expose their skin to sunlight due to the modern society they are living in, avoiding heat through shade and by means of air conditioning whether at home, work or in automobiles with shield windows up to $50 \%$. So, for those reasons the proper amount of sun is presumably not possible; and an oral form of vitamin D should be considered as supplement. High quality cod liver oil is probably the best choice, as it also supplies vitamin A that helps limit vitamin D toxicity and also beneficial omega-3 fats. Milk does provide vitamin $\mathrm{D}$, but only about 250 units per 8 ounces. The assumption that BIGINERS in Egypt are receiving the proper amount of an essential source to obtain vitamin $\mathrm{D}$ from fish, milk, and eggs, must be investigated. It will be important to take calcium while receiving vitamin $\mathrm{D}$, or it will tend to take calcium out of the bones. Finally, BIGINERS raised in such a society who are kept safe from sun exposure spend a great deal of time indoors with video hi-tech games, computers, play stations and watching TV.

\section{Purpose}

1- Assess health related physical fitness components for the sample in the study;

2- Test their vitamin D level using blood sample;

3- Determine their range body composition (BMD, FAT, LEAN MASS) status;

\section{Method}

\section{Sample}

The study sample $(\mathrm{N}=96)$ were males and females randomly chosen immediately after their involvement in the Summer Club at wadi Degla October Branch population consisting of 500 average age was12.9 \pm 1.6. Health related fitness components were modified and measured to suit the age group such as cardiovascular endurance(Modified Bruce protocol).

\section{Procedures}

In the present study BIGINERS were required to perform the maximal exercise test on a motor-driven treadmill. (Kilani, Al-Yarobi, Zayed, Alzakwani, Bererhi, Shukri, Alrasadi, 2013). Muscle strength (Dynamometer of Grip Strength) muscular endurance (Modified sit-up) and flexibility (Modified Flexibility). (Kilani,H.\&Lala,O., 2001) Body composition was tested including Lumbar spine and whole body BMD as well as body fat and lean masses were measured using DEXA Hollogic Delphi. Before the scanning, the height and weight of the BIGINERS were measured. Body composition measurements were performed using a Dual X-ray Absorptiometry (DXA), Hologic Delphi, $\mathrm{W}$ fan beam X-ray bone densitometer. The whole body was scanned and scan results were analyzed as follow. (Kilani, AlYarobi, Zayed, Alzakwani, Bererhi, Shukri, Alrasadi, 2013). 
The DiaSorin 25-Hydroxy Vitamin D assay consists of two-step procedure. The first step involves a rapid extraction of 25$\mathrm{OH}$ Vitamin D and other hydroxylated metabolites in serum or plasma with acetonitrile. Following extraction, the treated sample is then assayed using equilibrium RIA procedure. The RIA method is based on an antibody with specificity to 25-OH-D. The sample, antibody and tracer are incubated for 90 minutes at $20-25^{\circ} \mathrm{C}$. Phase separation is accomplished after a 20 minute incubation at $20-25^{\circ} \mathrm{C}$ with a second antibody precipitating complex. A NSB/Addition buffer is added after this incubation period to centrifugation to aid in reducing nonspecific binding. Bound radioactivity is inversely proportional to the concentration of 25-OH-Vitamin D.

\section{Statistical Analysis}

Descriptive statistics were used to describe the data. For categorical variables, frequencies and percentages were reported. Differences between groups were analyzed using Pearson's chi-square test (or Fisher's exact test for cells <5). For continuous variables, means and standard deviation and median and interquartile range $\left(25^{\text {th }}\right.$ and $75^{\text {th }}$ percentiles $)$ were used to present the data while analysis was performed using Student's t-test and Wilcoxon-Mann-Whitney, respectively. An a priori two-tailed level of significance was set at the 0.05 level. Statistical analyses were conducted using STATA version 12.1 (STATA Corporation, College Station, TX).

\section{Results}

The demographic and bone densitometry characteristics of the study sample $(\mathrm{N}=$ 96) are summarized in Table 1. Fifty-three percent of the cohort (51/96) has low vitamin $\mathrm{D}$ levels $(<50 \mathrm{nmol} / \mathrm{L})$. The overall mean age of the cohort was $13 \pm 2$ years with no significant differences in age among the two groups (12.8 versus 12.9 years; $p=0.856)$. Fifty-six percent (54/96) of the patients were females with the females more likely to be vitamin D deficient than males ( $82 \%$ versus $18 \%$; $p<$ 0.001). The overall mean weight, height and BMI of the study cohort were $42 \pm 15$ $\mathrm{kg}, \quad 147 \pm 12 \quad \mathrm{~cm}$ and $18.9 \pm 4.8$ $\mathrm{kg} / \mathrm{m}^{2}$,respectively, with no significant differences amongst the groups ( $p>0.05)$.

The bone mineral content (BMC), bone mineral density, fat mass, lean BMC, and lean mass are $1,263 \pm 344 \mathrm{~g}, \quad 0.84 \pm 0.1$ $\mathrm{g} / \mathrm{cm}^{3}, 9,775(5,852-15,234) \mathrm{g}, 29.4 \pm 8.7$ $\mathrm{kg}$, and $28.1 \pm 8.4 \mathrm{~kg}$, respectively, with no significant differences amongst the groups ( $p>0.05$ ). However, the vitamin D deficient group was associated with higher fat percent compared to those with normal vitamin $\mathrm{D}$ status $(29 \%$ versus $24 \% ; p=$ 0.011).

The association between vitamin $\mathrm{D}$ and various physical exercise attributes are stratified gender-wise (females and males) and presented in Tables 2, and 3, respectively. Grip scores were significantly higher in males than females (21 versus $15 ; p<0.001$ ). They were also significantly lower in vitamin D deficient participants in males (16 versus $23 ; p=$ 0.039 ) but not females (16 versus $13 ; p=$ $0.057)$. Females were also associated with higher flex scores (5.0 versus $-0.7 ; p<$ 0.001 ), lower sit-up scores (13 versus $16 ; p$ $=0.001)$, lower end-2 scores (131 versus $160 ; p<0.001)$, higher end-3 scores (176 versus $155 ; p<0.001)$, and higher end-4 scores (187 versus $180 ; p=0.008)$. There were no significant differences in all physical exercise attribute scores $(p>0.05)$ in females between those with normal and those with low vitamin D levels. These results were also replicated in males except for grip and end-2 scores for which those with low vitamin levels were associated with low (16 versus $23 ; p=0.039$ ) and high scores (150 versus $137 ; p=0.034)$, respectively 
Table 1: Association between Vit. D and various demographic and bone densitometry characteristics $(\mathrm{N}=9)$

\begin{tabular}{|c|c|c|c|c|}
\hline \multirow[b]{2}{*}{ Characteristic } & \multirow[b]{2}{*}{$\begin{array}{c}\text { All } \\
(\mathrm{N}=96)\end{array}$} & \multicolumn{2}{|c|}{ Vit D status } & \multirow[b]{2}{*}{$\boldsymbol{P}$} \\
\hline & & $\begin{array}{c}\text { Normal } \\
(\geq 50 \mathrm{mmol} / \mathrm{l}) \\
(\mathrm{n}=45 ; 47 \%)\end{array}$ & $\begin{array}{c}\text { Low } \\
(<50 \mathrm{mmol} / \mathrm{l}) \\
(\mathrm{n}=51 ; 53 \%)\end{array}$ & \\
\hline \multicolumn{5}{|l|}{ Demographic } \\
\hline Age, mean $\pm S D$, years & $12.9 \pm 1.6$ & $12.8 \pm 1.8$ & $12.9 \pm 1.4$ & 0.856 \\
\hline \multicolumn{5}{|l|}{ Gender, n (\%), } \\
\hline Female & $54(56 \%)$ & $12(22.2 \%)$ & $42(77.7 \%)$ & $<0.001$ \\
\hline Male & $42(44 \%)$ & $33(78 \%)$ & $9(21.4 \%)$ & \\
\hline Weight, mean \pm SD, kg & $42 \pm 15$ & $41 \pm 15$ & $43 \pm 15$ & 0.546 \\
\hline Height, mean \pm SD, cm & $147 \pm 12$ & $146 \pm 14$ & $147 \pm 11$ & 0.560 \\
\hline $\mathrm{BMI}$, mean $\pm \mathrm{SD}, \mathrm{kg} / \mathrm{m}^{2}$ & $18.9 \pm 4.8$ & $18.6 \pm 4.8$ & $19.2 \pm 4.8$ & 0.575 \\
\hline \multicolumn{5}{|l|}{ Bone densitometry data } \\
\hline BMC, mean $\pm S D, g,(N=86)$ & $1,263 \pm 344$ & $1,253 \pm 323$ & $1,270 \pm 363$ & 0.813 \\
\hline BMD, mean $\pm \mathrm{SD}, \mathrm{g} / \mathrm{cm}^{3},(\mathrm{~N}=86)$ & $0.84 \pm 0.10$ & $0.85 \pm 0.09$ & $0.83 \pm 0.11$ & 0.590 \\
\hline Fat mass, median (IQR), g, & $\begin{array}{c}9,775 \\
(5,852, \\
15,234)\end{array}$ & $\begin{array}{c}7,906 \\
(4,943, \\
13,641)\end{array}$ & $\begin{array}{l}11,734 \\
(7,011, \\
15,503)\end{array}$ & 0.044 \\
\hline Lean BMC, mean $\pm S D, k g$, & $29.4 \pm 8.7$ & $30.2 \pm 9.4$ & $28.7 \pm 8.1$ & 0.426 \\
\hline Lean mass, mean \pm SD, kg, & $28.1 \pm 8.4$ & $29.0 \pm 9.1$ & $27.4 \pm 7.8$ & 0.403 \\
\hline Fat percent, mean $\pm S D$, & $27 \pm 9$ & $24 \pm 10$ & $29 \pm 8$ & 0.011 \\
\hline
\end{tabular}

BMI=Body mass index;

$\mathrm{SD}=$ Standard deviation;

$\mathrm{IQR}=$ Interquartile range;

$\mathrm{BMC}=$ Bone mineral content;

$\mathrm{BMD}=$ Bone mineral density;

Analyses were evaluated using Pearson's chi-squared test, Fisher's Exact test, Student's t-test and Wilcoxon-Mann-Whitney test, wherever appropriate. 
Table 2: Association between vitamin $D$ and various physical exercise attributes $(N=97)$

\begin{tabular}{|c|c|c|c|c|}
\hline \multirow[b]{2}{*}{ Characteristic } & \multicolumn{3}{|c|}{ Vitamin D status } & \multirow[b]{2}{*}{$P$} \\
\hline & $\begin{array}{c}\text { All } \\
(\mathrm{N}=97)\end{array}$ & $\begin{array}{c}\text { Normal } \\
(\geq 50 \mathrm{nmol} / \mathrm{l}) \\
(\mathrm{n}=46 ; 47 \%)\end{array}$ & $\begin{array}{c}\text { Low } \\
(<50 \mathrm{nmol} / \mathrm{l}) \\
(\mathrm{n}=51 ; 53 \%)\end{array}$ & \\
\hline \multicolumn{5}{|l|}{ GRIP score $(\mathrm{N}=96)$} \\
\hline Mean \pm SD & $17.8 \pm 7.2$ & $19.9 \pm 8.7$ & $16.1 \pm 5.2$ & 0.009 \\
\hline Median $\quad$ (IQR) & $16(13,22)$ & $17(13,25)$ & $16(12,18)$ & 0.070 \\
\hline Low GRIP $\quad(<17)$ & $53(55 \%)$ & $21(47 \%)$ & $32(63 \%)$ & \multirow{3}{*}{0.0013} \\
\hline Normal GRIP (17/19) & $14(15 \%)$ & $4(9 \%)$ & $10(20 \%)$ & \\
\hline High GRIP $\quad(>19)$ & $29(30 \%)$ & $20(44 \%)$ & $9(18 \%)$ & \\
\hline \multicolumn{5}{|l|}{ SIT-UP score $(\mathrm{N}=96)$} \\
\hline Mean \pm SD & $14.6 \pm 5.4$ & $15.2 \pm 7.2$ & $13.6 \pm 3.1$ & 0.149 \\
\hline Median $\quad(I Q R)$ & $14(11,17)$ & $15(11,20)$ & $14(11,15)$ & 0.042 \\
\hline Low SIT-UP (<14) & $41(44 \%)$ & $16(37 \%)$ & $25(49 \%)$ & \multirow{3}{*}{0.016} \\
\hline Normal SIT-UP (14/15) & $23(24 \%)$ & $7(16 \%)$ & $16(32 \%)$ & \\
\hline High SIT-UP (>15) & $30(32 \%)$ & $20(47 \%)$ & $10(20 \%)$ & \\
\hline \multicolumn{5}{|l|}{ END 2 score $(\mathrm{N}=96)$} \\
\hline Mean \pm SD & $152 \pm 19$ & $144 \pm 19$ & $158 \pm 18$ & $<0.001$ \\
\hline Median & $\begin{array}{c}149(139 \\
163)\end{array}$ & $141(133,155)$ & $\begin{array}{c}157(143, \\
174)\end{array}$ & $<0.001$ \\
\hline Low END2 $\quad(>150)$ & $43(45 \%)$ & $14(31 \%)$ & $29(57 \%)$ & \multirow{3}{*}{0.024} \\
\hline Normal END2 (150/152) & $4(4 \%)$ & $2(4 \%)$ & $2(4 \%)$ & \\
\hline High END2 $(<152)$ & $49(51 \%)$ & $29(64 \%)$ & $20(39 \%)$ & \\
\hline \multicolumn{5}{|l|}{ END 3 score $(N=94)$} \\
\hline Mean \pm SD & $167 \pm 18$ & $161 \pm 18$ & $173 \pm 16$ & 0.001 \\
\hline Median & $\begin{array}{c}169(153, \\
184)\end{array}$ & $161(147,173)$ & $\begin{array}{c}174(165 \\
186)\end{array}$ & $<0.001$ \\
\hline Low END3 $\quad(>150)$ & $48(51 \%)$ & $14(31 \%)$ & $34(69 \%)$ & \multirow{3}{*}{$<0.001$} \\
\hline Normal END3 (150/152) & $5(5 \%)$ & $4(9 \%)$ & $1(2 \%)$ & \\
\hline High END3 $(<152)$ & $41(44 \%)$ & $27(60 \%)$ & $14(29 \%)$ & \\
\hline
\end{tabular}

$\mathrm{SD}=$ Standard deviation;

$\mathrm{IQR}=$ Interquartile range;

Analyses were evaluated using Pearson's chi-squared test, Fisher's exact test, Student's t-test and Wilcoxon-Mann-Whitney test, wherever appropriate. 


\section{Discussion:}

Vitamin D3 is synthesized in the skin and is present in oil-rich fish such as salmon, mackerel, and herring; which is not available in Egypt. Commercially available vitamin D3 is synthesized from the cholesterol precursor 7dehydrocholesterol naturally present in the skin or obtained from lanolin. Both vitamin D2 and vitamin D3 are used for food fortification and in vitamin $D$ supplements. Vitamin D that comes from the skin or diet is biologically inert and requires its first hydroxylation in the liver by the vitamin D-25-hydroxylase (25OHase) to 25(OH)D (Holick, 2007).

However, 25(OH)D requires a further hydroxylation in the kidneys by the 25(OH)D-1_-OHase (CYP27B1) to form the biologically active form of vitamin $\mathrm{D}$ $1,25(\mathrm{OH}) 2 \mathrm{D}(3,8) .1,25(\mathrm{OH}) 2 \mathrm{D}$ interacts with its vitamin $\mathrm{D}$ nuclear receptor, which is present in the small intestine, kidneys, and other tissues (DeLuca, 2004). $1,25(\mathrm{OH}) 2 \mathrm{D}$ stimulates intestinal calcium absorption (Christakos, et al 2003). Without vitamin D, only 10 to $15 \%$ of dietary calcium and about $60 \%$ of phosphorus are absorbed. Vitamin D sufficiency enhances calcium and phosphorus absorption by 30-40\%and $80 \%$, respectively (Heaney, 2004).

Since BIGINERS aged 9-18 yr. has a rapid growth spurt characterized by a marked increase in their requirement of calcium and phosphorus to maximize skeletal mineralization, the metabolism of 25(OH)D to1,25(OH)2D increases. In our study, vitamin $\mathrm{D}$ was deficit in high percentages for females and in moderate percentages in males which indicate none sufficient exposure to the sun light as it was assumed. Our results match those obtained in study conducted by Kilani, AlYarobi, Zayed, Alzakwani, Bererhi, Shukri, Alrasadi, (2013).In the past, BIGINERS of all races obtained most of their vitamin D from exposure to sunlight and drinking vitamin D-fortified milk, and therefore, they did not need to take a vitamin D supplement. However, BIGINERS are spending more time indoors now, and when they go outside ,they often wear sun protection that limits their ability to make vitamin D in their skin. BIGINERS and adolescents are also drinking less vitamin D-fortified milk. (Sullivan et al, 2005)

A systematic review and meta-analysis of 14 studies with a total of 31,424 participants revealed an association between vitamin $\mathrm{D}$ levels and depression which concluded that low vitamin D concentration is associated with depression.(Anglin et al 2013) Given the high prevalence of both vitamin D deficiency and depression, an association between these two conditions would have significant public health implications, particularly as supplementation with vitamin $\mathrm{D}$ and regular exercise under sun light for the skin exposure. However, vitamin $\mathrm{D}$ and depression may be linked is still unclear. Vitamin D deficiency may result in depression, or depression may increase risk for low vitamin D levels. For example, depressed people may spend more time indoors, and are less likely to eat a healthy diet and take care of themselves, all of which could affect vitamin $\mathrm{D}$ levels. On the other hand, there are vitamin $\mathrm{D}$ receptors everywhere in the body, including the brain. These receptors need vitamin $\mathrm{D}$ to do their job. More research is urgently needed to determine whether vitamin $\mathrm{D}$ can prevent and treat depression. Further investigation of this type of correlation need to be made on the sample of this study to see if the result obtained by Kilani, et al , 2013 was consistent.

In young BIGINERS who have little mineral in their skeleton, this defect results in a variety of skeletal deformities classically known as rickets. However, BMDs were not marked at this age group. In turn, the increased blood levels of 
$1,25(\mathrm{OH}) 2 \mathrm{D}$ enhance the efficiency of the intestine to absorb dietary calcium and phosphorus to satisfy the growing skeleton's requirement for these minerals during its rapid growth phase.

We can't assume that there were malnutrition since the optimal nutrition from various sources will not be sufficient for the sufficient production of vitamin D for the body. Therefore, the best sources to have vitamin $\mathrm{D}$ is from the sun light exposure to the skin. As we mentioned earlier and despite the fact that sun light is available almost all year round in Egypt, but heat is so hi that prevent kids from playing outside in the schools and most of the physical education classes for girls were substituted with other subject.

Vitamin D deficiency also causes muscle weakness; affected BIGINERS have difficulty Standing and walking (Holick, 2006). Our males who have vitamin D deficiency scored low in grip strength. Muscle weakness is a prominent feature of the clinical syndrome of severe vitamin D deficiency. Clinical finding sin vitamin Ddeficiency myopathy include proximal muscle weakness, diffuse muscle pain, and gait impairments such as a waddling way of walking.( Schott \& Wills 1976)

There is an inverse association of serum $25(\mathrm{OH}) \mathrm{D}$ and body mass index (BMI) greater than $30 \mathrm{~kg} / \mathrm{m} 2$, and thus, obesity is associated with vitamin D deficiency.(Wortsman et al 2000) BIGINERS in our study who have higher fat percentages $(29 \pm 8)$ were vitamin D deficiency. This is because the body fat sequesters the fat-soluble vitamin. When obese and no obese adults were exposed to simulated sunlight or received an oral dose of 50,000 IU of vitamin D2, they were able to raise their blood levels of vitamin $\mathrm{D}$ by no more than 50\%compared with non obese adults.

\section{Conclusion}

Our results showed that a high prevalence of the female are deficit in Vitamin D are susceptible to be early diagnosis osteoporosis due to their vitamin D deficit. Male BIGINERS were also at moderate risk of vitamin D deficiency. This indicates that BIGINERS at this stage should involve in physical activity program and meet the required sunlight exposure during all season to gain healthy life style. Therefore, we recommend screening for vitamin $\mathrm{D}$ deficiency in BIGINERS and adolescents at risk for deficiency especially in Egypt where a prevalence of inactivity, malnutrition, short sleep duration and unhealthy habits were reported. (Kilani, et al 2013)In addition, we suggest that obese BIGINERS should reduce their fat percentages by diet and exercise and increase time exposure of their skin to sunlight or are given at least two to three times more vitamin D for their age group to satisfy their body's vitamin D requirement. We also recommend prescribing vitamin D supplementation for muscle weaknesses prevention and to improve muscle strength with regular exercise.

\section{Recommendations}

1-The need for exposure to the sun's rays before 12 noon and $5 \mathrm{pm}$ and not in other times to prevent exposure to ultraviolet (UV)

2-The Need for attention to exposure the girls especially who wearing headscarves to sunlight's since they are more women prone to vitamin $\mathrm{D}$ deficiency and due to obscured by clothing to sunlight have thus cause osteoporosis

3-Attention feeding- Some supplements rich with natural vitamin $\mathrm{D}$ 


\section{References}

1. Anglin RE, Samaan Z, Walter SD, McDonald SD. (2013) Vitamin D deficiency and depression in adults: systematic review and meta-analysis. $\mathrm{Br} J$ Psychiatry pp.202:100-7. doi: 10.1192/bjp.bp.111.106666. PMID: 23377209 [PubMed in process]

2. Bass S, Pearce G, Bradney M, Hendrich E, Delmas PD, Harding A, Seeman E.(1998): Exercise before puberty may confer residual benefits in bone density in adulthood: studies inactive prepubertal and retired female gymnasts. J Bone Miner Res.; 13:pp500.507.

3. Christakos S, Dhawan P, Liu Y, Peng X, PortaA(2003) New insights into the mechanisms of vitamin D action. $J$ Cell Biochem 88:pp695-705

4. DeLuca H( 2004) Overview of general physiologic features and functions of vitamin D. Am J Clin Nutr 80(6 Suppl):1689S-1696S

5. Dook, J E.; Jams S, C.; Henderson, N. K.; Pice, R. I(1997): Exercise and bone mineral density in mature female athletes. Clinical Sciences Medicine \& Science in Sports \& Exercise. 29(3):pp291-296, March

6. Frey, J. Rebecca. . ( 2009 ) "Child Depression Inventory." Gale Encyclopedia of Mental Disorders. The Gale Group Inc. Encyclopedia.com. 6 Oct<http://www.encyclopedia.com>.

7. Heaney RP (2004) Functional indices of vitamin D status and ramifications of vitamin D deficiency. Am J ClinNutr 80(6 Suppl): 1706S-1709S

8. Heaney RP, eds. (2000) Nutritional Aspects of Osteoporosis. A SeronoSymposia S.A. Publication.New York, NY:SpringerVerlag New York, Inc..

9. Heaney RP. (2000) there should be a dietary guideline for calcium. Am J Clin Nutr.;71:pp658-670

10. Holick MF (2006) Resurrection of vitamin D deficiency and rickets. J Clin Invest 116:pp2062-2072

11. Holick MF (2007) Vitamin D deficiency. N Engl JMed 357:pp266-281

12. Holick MF (2008) Vitamin D: a D-lightful health perspective. Nutr Rev 66(10 Suppl 2):Spp182-S194

13. Holick MF, Chen TC, Sauter ER( 2007) Vitamin D and skin physiology: a Delightful story. J Bone Miner Res 22(Suppl 2):V28-V33

14. Holmes RP, Kummerow FA.(1983) The vitamin D status of elderly Americans. Am J Clin Nutr Aug; 38(2):335-9.

15. Janz, K. F., T. L. Burns, S. M. Levy, J. C. Torner, M. C. Willing, T. J. Beck, J. M. Gilmore, and T. A. Marshall. (2004). Everyday activity predicts bone geometry in children: The Iowa bone development study. Med Sci Sports Exerc.; 36:pp1124-1131.

16. Johnston CC, Millar JZ, Slemenda CW, (1992). Calcium supplementation and increases in bone mineral density in children. N Engl J Med:;327:pp82-87.

17. Kemmler,W., Engelke,K.,Baumann,H.,Beeskow,C., von,S. (2006): Bone status in elite male runners - European Journal of Applied Physiology, - Springer 
18. Kilani, H., Abu Eisheh, A. (2010) Optimum Anthropometric Criterion for Ideal Body Composition. SQU Med J, Vol. 10, Iss. 1, pp. 74-79.

19. Kilani, H, Al-Hazzaa, H, Waly, M, \&Musaiger, A. (2013) Lifestyle Habits: Diet, Physical Activity and Sleep Duration among Omani Adolescents. SQU Med J, in press.

20. Kilani, H., Al-Yarobi, S., Zayed, K., Alzakwani, I., Bererhi, H., Shukri, Alrasadi, K. (2013). Physical Fitness Attributes, Vitamin D, Depression, and BMD in Omani's Children. EuropSci J. 9(30), pp156-173.

21. Kilani, H.\&Lala, O., (2001): Physical activities, its relation to Health related fitness for pupils. Proceedings of the $1^{\text {st }}$ Educational Activity Conference,.Dubai,UAE Feb.pp25-27,

22. Lambert HL, Eastell R, Barker ME.(2000) Calcium supplementation in teenage girls with low dietary calcium intakes. Proceedings of the 4th International Symposium on Nutritional Aspects of Osteoporosis. May 17-20, Lausanne, Switzerland. In: Burckhardt P, Dawson-Hughes B,

23. Lehtonen-Veromaa M, Mottonen T, Heinonen OJ, et al. (2004) gain among per pubertal Finnish girls: a 3-year prospective

24. Moan J, Porojnicu AC, Dahlback A, Setlow RB( 2008) Addressing the health benefits and risks, involving vitamin $\mathrm{D}$ or skin cancer, of increased sun exposure. Proc Natl Acad Sci USA 105:pp668-673

25. Nowson CA, Green RM, Hopper JL, (1997). A co-twin study of the effect of calcium supplementation on bone density during adolescence. Osteoporosis Int.;7:pp219-225.

26. O'Connor JA, Lanyon LE, MacFie H.:(1982) The influence of strain rate on adaptive bone remodelling. J Biomech;15(10):pp767-81.

27. Saxon,L, Robling,A, .Alam,I,Turner,C:(2005) Mechanosensitivity of the rat skeleton decreases after a long period of loading, but is improved with time off. Bone, Volume 36, Issue 3, pp 454-464

28. Specker BL.(2000) Should there be a dietary guideline for calcium intake? No. Am $J$ Clin Nutr.;71:pp661-664.

29. Stear SJ, Prentice A, Jones SC, Cole TJ.(2000) Bone mineral status of female adolescents 14 months after the cessation of a calcium and exercise intervention. Osteoporos Int.;11(suppl 2):S84.

30. Sullivan SS, Rosen CJ, Halteman WA, Chen TC, Holick MF (2005) Adolescent girls in Maine at risk for vitamin D insufficiency. J Am Diet Assoc 105:pp971-974

31. Sullivan, P.G., Dube, C., Dorenbos, K.D., Steward, O., Baram, T.Z., (2003). ... agerelated, alterations in mitochondrial responses to elevated calcium. ... Rho, J.M.

32. Wortsman J, Matsuoka LY, Chen TC, Lu Z, Holick MF (2000) Decreased bioavailability of vitamin D in obesity. Am J Clin.Nutr. 72:pp690-693 